\title{
PRESERVATION AND DEVELOPMENT WITHIN THE NATURAL AND SOCIAL EVOLUTION
}

\author{
Nadezhda Subbotina ${ }^{1}$
}

\begin{abstract}
Investigation of the social evolution process and its differences from the natural evolution requires methodological substantiation. This article proposes a methodological approach based on the Hegelian dialectics. We distinguish two types of development: development based on external premises and development based on own foundation (self-development). The dialectics of preservation and change shows itself differently among these types.

Social evolution is a new branch of the global evolution; its motion vector is directed toward big changes and acceleration. At the same time, the speed of natural evolution remains slow. Emerging "scissors" create tension between the human's natural and social sides. Natural evolution requires a person to perform the preservation functions, while social evolution requires changing functions.
\end{abstract}

UDC Classification Numbers: 101, DOI: http://dx.doi.org/10.12955/cbup.v2.463

Keywords: social evolution, dialectics, identity, difference, preservation, changing, development

\section{Introduction}

The fact of social origin from nature is not questioned by modern science and the majority of philosophical directions. The scientific and philosophical researches of social origin and its formation process lack methodological argumentation. There are general patterns of the origin of new phenomena on the basis of the existing ones. The major significance is in the understanding of the two types of development: the development based on external conditions and the development on the basis of internal conditions (its own premises). Justification of these types of development can be found in the doctrine of dialectical development. Hegel (1972) showed that every new phenomenon occurs in the depths of the old, "the appearance which is thus created does not stand on its own feet, and has its being not in itself but in something else." Old phenomenon contains the terms (backgrounds) for the emergence of the new, "really however, an immediate actuality of this kind includes in the germ o something else altogether."

In the development of this new, these premises are dialectically abolished (Aufheben term.), according to Hegel (1972) they lie in the base of the new, "the conditions which are sacrificed, which feel to the ground and are spent, only unite with themselves in the other actuality, and new finds its own basis for development.”

\section{Two types (stages) of development}

Therefore, the process of development can be divided into two stages: (1) the development based on external premises (development as the establishment) and (2) the development based on internal premises (development as improvement). Each of the selected stages by Hegel has so strongly pronounced high-quality distinctness that it can be defined as a separate type of development.

Type of development based on external premises results mainly in: external determination of the developing object or phenomenon, its lack of independence, instability, and greater dependence on the external conditions of its existence. External premises affect the form (and sometimes the content) of the object of development, but at the same time they may not define the specifics and matter of the object. Yet, the first type of development serves as a variant of self-development and self-regulation, since an evolving subject uses external development premises, embedded in its own structure itself, and it responds to changes in conditions of its existence itself.

\footnotetext{
${ }^{1}$ Nadezhda Subbotina, Zabaikalsky State University, Russian Federation, profsubbotina@gmail.com
} 
Type of development based on its own premises is typical for the already formed objects and manifests itself as further development. This type is more resistant, autonomic, and less dependent on the external conditions of its existence and the accelerated development. Such a development may be considered as a genuine self-development.

External premises are the building blocks of the emerging system and determine the geometry of its external form to a great extent. According to synergetics, there is a self-organizing process characterized by the spontaneous emergence of ordered sustainable structures and functions of the originally disordered, and unregulated forms in self-developing systems.

The mentioned types of development are manifested in the establishment and improvement of both the material and spiritual systems - both in individual and in historical development. That fact speaks of their universality. In all complex objects and phenomena, both types of development may simultaneously be present because parts or constituent elements (with relatively independent evolution) of these objects and phenomena can be based both on internal and on external conditions. The history of mankind gives us an example of one of the most striking manifestations of the two types of development. The given types can be traced both in establishing certain social phenomena, and in the development of society as a whole.

\section{The dialectics of identity and difference in the evolution}

Any evolution, just like any other development, is impossible without preserving the achieved results. Therefore, mechanisms of development should involve the mechanism for the preservation of useful results as their integral part. However, preservation and development are not simple opposites.

As is known, Hegel (1971), in his dialectics, opposed the notions of identity and difference. If we think of these categories in the materialistic sense, it is obvious that they are connected with the functions of conservation and change. Change prevails in the first stage of development of objects and phenomena (development based on external premises or development as formation). It is the process of abolishing external premises and constructing of own foundation. In the second stage (development based on internal premises, genuine self-development), conservation prevails, i.e. the system tends to be identical to itself. However, the absolute identity is impossible. Hegel (1971) stressed, "it is important to come to a proper understanding on the true meaning of Identity; and, for that purpose, we must especially guard against taking it as abstract Identity, to the exclusion of all Difference.”

Therefore, there is also a difference in the form of various fluctuations in the system with predominance of identity, which performs a preservation function (Figure 1).

\begin{tabular}{l} 
Figure 1: Dialectics of the Identity and the Difference manifestation in processes of preservation, \\
changing, development and death \\
\hline Source: Author
\end{tabular}


Throughout the existence of any system, there are preservation and development. At the system establishment stage, as a result of the "successful" changes, the development prevails. This development is based mainly on external premises. At the stage of improvement, the development continues, but conservation dominates. The system tends to the sustainability and conservation of its "successful" changes. The mechanisms for system conservation are formed in the process of its development; the system constantly strengthens its acquisition. For example, the memory of successful adaptations is accumulated in the biological evolution, and the mechanism of pre-adaptation is based on this memory.

The dialectics of preservation and change is present in the natural and social evolution; but in the social evolution, their correlation varies. This affects human being and creates the inconsistency in his or her behavior. The natural evolution requires a person to perform the functions of preservation, as well as the social one-the function of change.

The main mechanism of natural evolution is natural selection, due to which the following remain: (1) individuals with successful mutations; (2) the mutations themselves, being fixed in the gene pool of the population; and (3) the population itself, adapting to changes in the external environment. The prevalence of preservation here is not the subject to doubt; therefore, the function of preservation of the self-organizing living system is the leading function. The number of changes is much fewer and if there is a failed mutation or an individual manifests an unexpected behavior, it may die. However, change can also perform the function of preservation for the system by means of its development (having a more robust structure, new functions). Alternatively, ergodic system returns to the previous balance, but with the help of a different method.

Some of the manifestations of social evolution, having the resemblance with the same phenomena of natural evolution, are essentially different at the same time. Moreover, there are those features of social evolution, which the natural one does not have.

Boyd \& Richerson (1998) wrote that changing of people's existence from living in small kinship groups to life in huge communities with the emergence of farming culture represents a real "evolutionary puzzle." They noted that the human societies exceed the communities of ants, termites or corals by number of members and complexity. However, "human social complexity is based on quite different principles than the ultra-sociality of any other species. In all other known cases, the constituent individuals of societies are either genetically identical, as in the colonial invertebrates, or closely related, as in the social insects and non-human mammals." Complex organization of our ancestors is related to "cultural transmission of adaptive information." Thus, sociality as a product of natural evolution has made a qualitative leap. Boyd \& Richerson (1998) called this phenomenon "human ultra-sociality." The scientists considered that the relationship of culture and cooperation of our ancestors had the advantage in the rapidly changing conditions of the Pleistocene. Our ancestors began to create socio-technological traditions through cultural transmission. "Some of these processes have the effect of making group selection on cultural variation possible and the use of cultural cues to structure populations common.” Because of this acquisition, people are able to create and can change almost unlimited social systems.

The opportunity to receive adaptive information through cultural transmission plays a great role here. The article “A Bayesian approach to the evolution of social learning," by Perreault, Moya, \& Boyd (2012), stated "social learning is an essential part of human adaptation and is likely a key factor generating our remarkable ecological success over the last 50,000 years.” This happened because "unsurprisingly, when the environmental information is accurate, natural selection favors individuals who put a lot of weight on it” (Perreault, Moya, \& Boyd, 2012). Precisely, the complication of social relations was the main manifestation of the man evolution. So, our ancestors developed, first, the 
ability to navigate in inter-group relations. Knowledge of nature took the second place in the development of human intelligence.

Grinin, Markov, \& Korotaev (2009) referring to Hallpike (1986) and relying on their own conclusions, distinguished the differences between the biological and social evolution on three levels. The following is an abridged excerpt taken from Grinin, Markov, \& Korotaev, 2009:

"A. The level of the individual company and the organism

1. As pointed out by Hallpike, societies are able to change (transform) to the extent which is not observed in the prehumen organic world (Hallpike, 1986, p. 33). However, societies may not simply be changed and transformed, but they are able to adopt innovations and new elements.

2. They can be transformed consciously and with a definite purpose.

3. In the course of social evolution, one and the same social and political organism can be changed radically repeatedly.

4. Transfer of the key information and biological and social evolution is very much different in the sense of prototypes fidelity.

5. Acquired characteristics are not inherited in the biological evolution, and thus, have no impact on biological evolution, which is extremely slow in that case.

6. Although there is a significant (actually 'system') similarity between biological and social organisms, they are fundamentally different in the possibility to evolve. The biological body itself is not evolving; biological evolution can only occur on a higher level (population, species levels). Social evolution is quite apparent on the level of a single social organism, and it's also possible to trace the evolution of individual institutions or subsystems inside."

We would like to make a significant remark on the last point of the quotation. From our point of view, though social systems are called "social structures" because of Spencer ${ }^{2}$, they should be compared not with biological organisms but with groups of biological organisms-different taxa. The similarities here are much more explicit than the similarities between society and the biological organism. In addition, the evolution of society should be compared not with the evolution of biological organisms (which do not exist as a separate type as known) but with the evolution of taxa. Moreover, if elements of the population are biological specimens, the elements of social systems are people; they do not evolve per se, so in this paragraph their similarities are manifested, not the differences between the two evolutions.

Therefore, the researchers found the differences in the manifestation of some evolutionary mechanisms that emerged in social evolution. There is a question about the reason for these features' presence. In our view, these reasons are more like common differences of social evolution, which give rise to all the others (and not just those listed here).

In short, the main differences of social evolution from a natural one are as follows:

- subjective factor has the increasing impact on the social evolution;

- at the stage of civilization, it acquires the quality of awareness;

- as a consequence of awareness, an acceleration in social evolution increases, creating a trend of entering the mode of exacerbation and singularity;

- the "goals" of evolution change. For the natural evolution, the dominant, but not conscious, "goal" is preservation; while development is only a minor result of adaptation here. The development is present in the social evolution from the very beginning; in fact, the social

\footnotetext{
${ }^{2}$ Herbert Spencer (27 April 1820 - 8 December 1903) was an English philosopher, biologist, anthropologist, sociologist,and prominent classical liberal political theorist of the Victorian era (http://en.wikipedia.org/wiki/Herbert_Spencer).
} 
evolution itself is the result of mechanisms of natural evolution, and its subject-society (human) is the result of the development of nature.

The natural evolution was moving toward an increase in preservation. Perhaps quantitative accumulation led to the opposite qualitative result. The human society, due to the emergence of consciousness, received a margin of safety in the environment. The society felt so confident that it not only began to develop in the direction of adaptation to external conditions, but also began to cultivate itself as it wanted.

The evolution of man was carried simultaneously with social evolution. However, this process is much more complex and contradictory. A primary element of the natural evolution is not an individual, but the population. The role of the primary elements of social evolution is also performed by community groups, and not by man. Thus, two contradictions emerge here. First, a man endowed with consciousness, self-awareness, and the ability to self-identify is not willing to be a passive elementthe object of evolution. Second, there is also an acute contradiction between the social and natural evolution, leading to contradictory essence of man.

\section{The problem of periodization of universal evolution}

Scientists have different approaches to the allocation of the stages of evolution, but in most cases they determine three classic stages: formation of inanimate matter, the formation of the biosphere, and the origin of man and society. For instance, these three stages of evolution are acknowledged by the authors of the almanac "Evolution: Cosmic, Biological, and Social" (Grinin, Carneiro, Korotayev, \& Spier, 2011), as it is seen from the title of the work. Damste (2009) also considered three stages of evolution, calling them "cosmic, biological, and cultural."

Barrett (2010) believed that all products of evolution (atoms, cells, and humans) have consciousness because "they all have awareness with a purpose, and the purpose of all entities is to attain, maintain or enhance their internal stability and external equilibrium-to survive and thrive." They need the consciousness to deal with external threats. Therefore, he believed that "we can identify three significantly different types and stages in the evolution of consciousness-atomic consciousness, cellular consciousness, and human consciousness (an advanced form of creature consciousness). Each type of consciousness differentiates itself from the preceding type of consciousness by its ability to handle greater levels of complexity” (Barrett, 2010).

Contemporary universal evolutionism "assumes that space, chemical, geological, biological and social types of macro-evolution have a genetic and structural continuity” (Grinin, Markov, \& Korotaev, 2009). These stages of evolution can be divided into two larger stages: the evolution of the inorganic world (space, chemical, and geological) and evolution of the living world. However, the second stage is logically divided into two qualitatively distinct periods - the evolution of biosphere and the evolution of society (Figure 2).

Figure 2: First periodization of evolution

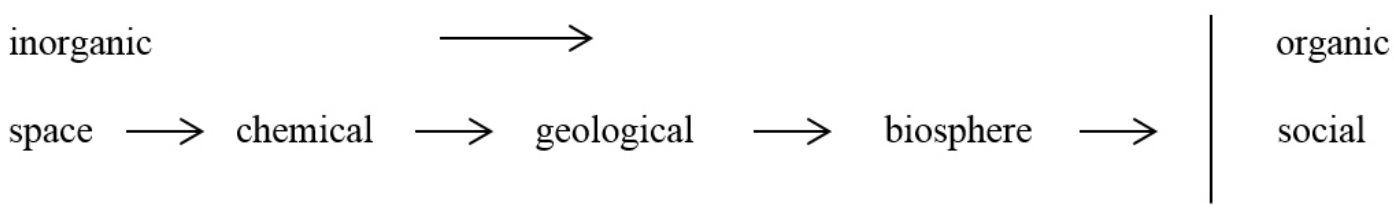

Source: Author 
Researchers rightfully referred to the unity of the biosphere and society evolution such that "we can talk about the evolution of the biosphere in a generalized sense, considering the evolution the biosphere itself and the evolution of mankind as a single continuous process" (Panov, 2008). Planetary system, which refers to such a system, "which in the early stages of development is identified with the biosphere in the common sense, and includes civilization in the later stages of its evolution,” is called an evolving system (Panov, 2008).

However, there is one other variant of the selection of two qualitative stages of evolution if we consider the common in the evolution of the biosphere with the early stages of macroevolution, i.e. the fact that they were and are, in the their majority, slow, spontaneous, and without any influence of a subjective factor. This stage is the natural evolution. Social evolution can be considered as the highest evolutionary stage not only of the planetary system, but also of the evolution of our universe as a whole (Figure 3).

\begin{tabular}{|l|l|l|}
\hline Figure 3: Second periodization of evolution & & social \\
natural & $\longrightarrow$ & social \\
space $\longrightarrow$ chemical $\longrightarrow$ geological $\longrightarrow$ biosphere $\longrightarrow$ & \\
\hline Source: Author
\end{tabular}

Though the emergence of social evolution does not mean the end of the natural one, the beginning of the anthroposoziogenese acted as the bifurcation point for our ancestors, and the vector of their development was directed at an angle to the continuing natural evolution. Therefore, one can say that social evolution is a stage of global evolution, and consider it as a special branch within the evolution of the planetary system. Then, not only the society itself, but also the mechanisms of its evolution have natural, external premises of development. Gradually, social evolution "captures leadership" and natural biological evolution becomes its "side branch," whose fate depends entirely on the behavior of the product of social evolution-man. People cannot have a large impact on the space, but they may influence the living world of the planet-the biosphere.

The reason of the increasing acceleration, or "acceleration with the aggravation," of social evolution, in our opinion, lies in the fact that preservation part of the functioning (activity) of any social system decreases because of consciousness; and changing part increases (towards the development or towards degradation), thus "breaking" thus the natural laws of evolution.

The further the society goes from prehistory, the more often the successive periods of pre-eminent development and preservation replace each other. This is a consequence of the acceleration of evolution and instability of society. The acceleration cannot be canceled. It is immanent to man, as a species, and it is the subject to the laws of evolution itself.

Panov (2008), analyzing the singularity, concluded that "it is a process, accelerating in the mode of exacerbation, when some system parameters tend to infinity in finite time... In this case the number of phase transitions in a unit of time tends to infinity.” Mathematical calculation, made by Panov (2008), showed that the point of singularity, the value of which tends to infinity, is the first half of the $21^{\text {st }}$ century. A supporter of the technological singularity, Vinge (1993), argued that in the nearest future (around 2030), modern super technologies will rise to a qualitatively new mind (superhuman intellect), and therefore, it is impossible to predict the future of mankind at the level of modern intelligence. As a reason for this, Vinge (1993) stated, "we humans have the ability to internalize the world and conduct 
'what if's' in our heads; we can solve many problems thousands of times faster than natural selection. Now, by creating the means to execute those simulations at much higher speeds, we are entering a regime as radically different from our human past as we humans are from the lower animals.” The result of a long development of the society, an attempt to resolve the contradictions in the natural and social evolutions, and the response to one of the eternal questions: society for man or man for society is the idea of humanism. It is impossible to answer this question by ignoring the specifics of the social system and man's place in it. Man, as an element of the social system, is qualitatively different from the elements of all other systems.

\section{Man for society and society for man}

Society was first established due to natural evolution as a natural self-organizing system. As in any other similar system, its elements (in this case, people) initially served only for its self-preservation. This refers to a form of interaction of the society (a group, a system, or the whole) or a person (an individual or an element of the system). That is, man was not a goal but a means. From the point of view of objective laws, a person is a "construction material" for society; individuals originally were of no value, so they could be sacrificed, if it was necessary for the system. In addition, the activities of a person at any level of the social hierarchy, taken together, provide self-preservation and development of the social system. The same was manifested in each separate group of people - the big or the small.

However, the social system of the society is qualitatively different from the natural systems. Many classical philosophers, e.g. Plato, Aristotle, etc., understood society as a rigid system, whose elements performed specific functions. But society is not the body and, moreover, not a mechanism. It refers to systems consisting of subsystems, with certain degrees of freedom. Even animal populations are such systems. And, man is much freer in the system of society. This led to one of the contradictions of a person as a result of the simultaneous natural and social evolutions. The natural evolution created a human being as a collective one. Nevertheless, the man of the era of civilization started to resist the fact that the society was using him as a means of self-preservation according to the principle of "man for society." The principle of "society for man" appeared as an alternative to the first principle and as the basis for the ideas of humanism. This principle found its expression in Kant's statement that "always recognize that human individuals are ends, and do not use them as means to your end." However, the ideal of Kant is unreachable; every person is a tool to achieve the objectives of other people or social structures. The principle of absolute value of a person, without the recognition of universal values, inevitably leads to social cataclysms. Both of these principles, contradicting one another, are unacceptable extremes; and the way to resolve this contradiction is to realize that society, along with nature, is a necessary condition for human existence. Providing for this condition requires the preservation of society. In our opinion, human right is "to be the goal," and his duty is "to be the means.”

Development of philosophy and ethics, raised awareness of not only the value of a particular individual, but also the value of every other person and society as a whole. The principle of "man for society and society for man" emerged as an ideal. It reflected the objective fact that the society and the people are the conditions for coexistence of one and the other. According to Hegel's triad method, such a principle is a logical synthesis of the previous two. This principle does not contradict the idea of humanism. It is a natural result of the idea's development if to understand the society not only as the supra-individual formation, but also as a collection of people. This principle was the basis for the humanism ideas in its modern secular interpretation. 


\section{Conclusion}

To sum up, the reason for the emergence and exacerbation of the contradictions between the natural and social evolution is the difference of their speed. For biological evolution, moderate increase of the speed is good. When the speed of social evolution exceeds the adaptive possibilities of the human body, the border measures are violated, and the degree of the unity of conservation and change is broken. The growing prevalence of changes leads to a qualitative leap. We do not know, in what form the leap will happen. Perhaps, it will be a singularity, the consequences of which are unpredictable. There is still no definite answer to the question, "have we already passed the point of no return yet?"

The fate of man, "the king of nature," is tragic because multi-vector of the natural and social evolution creates a kind of "scissors" and gradually "breaks" man. This is because the angle formed by the vectors of these two evolutions, is constantly expanding. The conflict between the natural and the social sides of man has emerged and it is gradually escalating. The natural evolution has formed the qualities with predominating functions of preservation in man; a social one is forming more new qualities leading to social changes. This gives an impetus to further accelerating the process of social evolution, but, at the same time, creates a lot of risks for the society. In social evolution as well as in the natural one, there is a dialectics of preservation and development. But, since people realized their opportunities to influence the evolution, they put progress (perfecting, as they see it) at the first place. It makes their existence unsustainable; the threat to preservation appears. That is, if in the biological evolution the changes (good or bad) are the result of random mutations, in the social one they are the result of people's free actions. These changes may be either helpful or harmful.

The principle of "man for society" means not only that each of us should do something meaningful for other people, but it also means that the main attention should be paid to preserving the society. Because we are the elements of society, its preservation is also our self-preservation. Social evolution has generated abstract ideas and creativity, and the human qualities, which are able to change the society. The fate of humanity now depends on what the change leads to-destruction or development. Of course, according to synergetics, chaos is the basis for the emergence of a new order, if it covers not a specific region, but the entire human world. And, the arising new order will not be ours, not a human one.

\section{References}

Boyd, R., \& Richerson, P. J. (1998). In I. Eibl-Eibisfeldt \& F. Salter (Eds.), The Evolution of Human Ultra-sociality. Ideology, Warfare, and Indoctrinability (pp. 71-95). Berghan Books.

Damste, P. H. (2009). Concentric man: Human systems of communication, adaptation and defence learning to communicate. Retrieved May 5, 2013, from https://sites.google.com/site/concentricman/

Grinin, L. E., Carneiro, R. L., Korotayev, A. V., \& Spier, F. (Eds.). (2011). Evolution Cosmic, Biological, and Social. Volgograd: Uchitel Publishing House.

Grinin, L. E., Markov, A. V., \& Korotaev, A. V. (2009). Makroevolyutsiya v zhivoy prirode i v obshchestve [Macroevolution in nature and society]. Moscow: Librokom publishing house.

Hegel, G. W. F. (1971). The Encyclopedia of the Philosophical Sciences, Vol. 1, translation by Humphrey Palmer, or The Logic of Hegel. In W. Wallace (Trans.), The Encyclopedia of the Philosophical Sciences, (pp. 52-361). Retrieved April 1, 2013, from http://www.naturalthinker.net/trl/texts/Hegel,G.W.F/Hegel,_G.W.F._-_Encyclopaedia_of_the_Philosophical_ Sciences_Part_One.pdf

Panov, A. D. (2008). Yedinstvo sotsial'no-biologicheskoy evolyutsii i predel yeyo uskoreniya [The unity of the sociobiological evolution and the limit of its acceleration]. Historical psychology and sociology history, 2, 25-48.

Perreault, C., Moya, C., \& Boyd, R. (2012). A Baysian approach to the evolution of social learning. Evolution \& Human Behavior, Proofs. Retrieved December 15, 2013, from http://www.sscnet.ucla.edu/anthro/faculty/boyd/Publications

Snooks, B. R. (2010). The Universal Stages of Evolution. Retrieved September 10, 2013, from http://www.valuescentre.com/ uploads/2010-04-19/The Universal Stages of Evolution Lessons for Leadership Development.pdf

Vinge, V. (1993). The Coming Technological Singularity. Retrieved September 15, 2013, from http://www.accelerating.org/ articles/comingtechsingularity.html 